\title{
A (R)EVOLUÇÃo digITAL E OS DILEMAS PARA A CATALOGAÇÃo: OS CIBERTECÁRIOS EM ATUAÇÃO
}

\author{
THE (R) EVOLUTION AND THE DIGITAL DILEMMA FOR CATALOGUING: \\ THE CIBERTECÁRIOS IN ACTION
}

\section{Jorge Santa Anna ${ }^{1}$}

\begin{abstract}
RESUMO
A (r)evolução digital se apresenta como um dilema impactante nos serviços biblioteconômicos da pósmodernidade. Diante das complexidades que apresentam o ambiente virtual, especificamente ao processo de organização da informação, este estudo objetiva refletir sobre as transformações acometidas ao fazer do catalogador em meio à revolução digital da pós-modernidade. Com esse propósito, por meio de revisão na literatura biblioteconômica da atualidade, discute-se alguns aspectos relacionados a essas transformações, como: o impacto da revolução digital e seus reflexos aferidos à prática da Catalogação; a evolução da biblioteca em meio ao desenvolvimento tecnológico; os novos desafios elencados na organização da informação, e por, fim, discute-se o novo espaço de trabalho do bibliotecário diante das novas tecnologias, sobretudo os impactos condicionados aos fazeres do catalogador. Por fim, evidenciou-se que o catalogador deve sofrer uma metamorfose profissional, adquirindo o perfil de cibertecário, sendo necessário para consumação desse feito, sua formação continuada e o desenvolvimento das qualidades de um moderno profissional da informação.
\end{abstract}

PALAVRAS-CHAVE: Tecnologia da informação. Organização da informação. Catalogação. Formação continuada. Cibertecários. Preservação digital.

\begin{abstract}
Reports the experience of the project of digitization and online publication of Essential rare works collection in biodiversity of the Museu Paraense Emílio Goeldi (MPEG). The initiative is the Biodiversity Heritage Library (BHL), whose purpose is to subsidize, the strengthening and development of scientific information and communication infrastructure, biodiversity and the environment. The purpose of study is to show the project of digitization and online publication of Essential rare works collection in biodiversity of the Museu Paraense Emílio Goeldi and study the role of digital preservation in the bibliographic collection special, using the criteria of digital preservation and document management. Allowing the construction of a conceptual schema to add and save the information, giving immediate access, by means of networks and sources of information, both national and international. The methodological course adopted was conducted through an exploratory research of descriptive character, based on literature as in books, journals, dissertations, theses and scientific articles already published addressing the theme. This mode is most relevant issues examined in the study, with respect to the methods related to the preservation of a bibliographic collection in digital formats. In this sense, scanning is combined with digital preservation in the collection on biodiversity, and will bring enormous contribution to the library of MPEG, making scientific information more accessible, giving continuity to the memory and making sure the absolute excellence of digital media, covered by technological innovations that will remedy their future losses.
\end{abstract}

KEYWORDS: Information technology. Information organization. Cataloging. Contining education. Cyberlibrarian. Digital preservation.

\footnotetext{
1 Graduado em Biblioteconomia pela Universidade Federal do Espírito Santo (UFES). Professor de Departamento de Biblioteconomia da UFES. Pesquisador atuante no ramo da Consultoria Informacional e Normalização de Trabalhos Científicos. E-mail: jorjao20@yahoo.com.br

Recebido em: 06/10/2014 - Aceito em: 11/03/2015
} 


\section{INTRODUÇÃO}

A evolução das bibliotecas é fruto das transformações e necessidades inovadoras desenvolvidas pelas sociedades ao longo dos tempos. Condicionadas, a priori, a armazenar o conhecimento produzido pelas nações, com vistas a transmiti-los a gerações futuras, essas instituições se transformaram em locais interativos e dinâmicos, em prol da democratização e socialização da informação, tendo em vista a produção acelerada de conhecimento.

$\mathrm{Na}$ atual conjuntura, a biblioteca vem se constituindo como um espaço destinado a fornecer o acesso a todo tipo de fonte de informação a qualquer usuário, desprendendo-se as limitações de tempo e espaço. Esse processo de interação da biblioteca com seus públicos, sem medir as fronteiras geográficas somente é conseguido com o apoio das novas tecnologias da informação e comunicação (TICs), ocasionando um processo acentuado de desterritorialização.

A biblioteca do futuro caminha para a virtualização, condicionando todos os fazeres bibliotecários para a forma virtual, mediada por meio do uso do computador e da internet. Segundo estudo realizado por Cunha (2010) a biblioteca tenderá a adaptar-se às inovações tecnológicas a fim de atender com precisão as necessidades dos usuários, que requerem informações cada vez mais instantâneas.

No decorrer dos últimos anos do século XX e início do século XXI, inúmeros estudos discutem previsões um tanto exageradas. Segundo Dias (2007), especulava-se em 1977 que em dez anos, o papel seria extinto e nos anos 90 os serviços seriam exclusivamente automatizados. Mas essas considerações não se concretizaram, caminhando a passos lentos.

Passados dez anos, um segundo estudo proclamado por Cunha (2010) demonstrou que as bibliotecas passam pelas gloriosas e rápidas transformações, não atingido ainda seu estado evolutivo. Concentram-se em um período de transição, localizadas na encruzilhada, definindo-se aos poucos, aderindo aos recursos informatizados oferecidos pelo ambiente ciberispacial.

Parece digno de louvor, afirmar que o sonho idealizado por Borges (1972), de que a biblioteca atingiria um estágio, um patamar evolutivo, em que poderia abarcar todo o conhecimento produzido pela humanidade, transmitindo-o a todas as localidades do mundo, sem considerar as limitações de tempo e espaço. É um tanto espantoso e curioso afirmar que a biblioteca de Babel idealizada por Borges deixa de ser uma utopia e se torna uma realidade, consumada a partir da biblioteca digital.

Para Drabenstott e Burman (1997, p. 1) a biblioteca digital remete a uma nova concepção de mundo, em que a informação está em formato "[...] onipresente e digital, sob custo razoável, em todo o tipo de mídia, disponível a qualquer pessoa, vinda do computador, televisão ou outras novas tecnologias tão comuns, universal como uma torradeira". O ambiente virtual está refletido por inúmeras complexidades. Essas especificidades se encontram com maior frequência no processo de organização da informação, o qual requer 
novas formas de tratamento, com vistas a melhorar a recuperação da informação e o desempenho dos sistemas de recuperação, o que remete à necessidade de construção de novas metodologias (KURAMOTO, 2006).

Com essas transformações advindas das TICs, o fazer profissional do catalogador que organiza a informação em ambiente digital deverá ser revisto, visando construir novas práticas que atendam as tendências desse novo espaço de atuação bibliotecária. Com isso, este estudo ${ }^{2}$ objetiva refletir sobre as transformações acometidas ao fazer do catalogador em meio à revolução digital da pós-modernidade.

Para tanto, através de revisões na literatura da área, este artigo propõe discussões acerca da revolução digital e seus reflexos aferidos à prática da Catalogação; a evolução da biblioteca em meio ao desenvolvimento tecnológico; os novos desafios elencados na organização da informação, e por fim, discute-se o novo espaço de trabalho do bibliotecário diante das novas tecnologias, sobretudo os impactos condicionados aos fazeres do catalogador.

Metodologicamente, a fim de fomentar as discussões, foram escolhidas algumas obras renomadas e atuais que retratam a temática em questão. A respeito da (r)evolução tecnológica nas bibliotecas, utilizou-se como principais estudos, os artigos de Cunha (2010), Alvarenga (2006), Dias (2007) e Ohira e Prado (2002). Em relação aos impactos das novas tecnologias ao processo de organização da informação, adentrou-se, como estudo de maior importância, as pesquisas de Dias e Naves (2007). No que se refere às reflexões sobre os novos serviços e produtos de catalogação foram utilizados artigos de Dias e Naves (2007), Campos (2007), Gonçalvez e Souza (2013), Vidal e Café (2011), Currás (2010) e Silva (2012). Por fim, o novo espaço de trabalho e postura do catalogador, tornando-se um cibertecário foi sustentado pelos estudos de Madureira e Vilarinho (2010) e Baptista (2004).

\section{TECNOLOGIA DA INFORMAÇÃO E SEUS REFLEXOS: A CONSUMAÇÃO DA BIBLIOTECA DO FUTURO}

As novas tecnologias vêm conquistando cada vez mais espaço e reconhecimento na sociedade contemporânea. Nos mais diversos cenários e segmentos sociais, elas se consolidam como uma alternativa viável para o gerenciamento do crescente volume de informações que são produzidas e disseminadas.

É práxis que as bibliotecas são consideradas, desde sua criação, como instituições mais apropriadas para organizar e gerenciar o conhecimento produzido pela humanidade, servindo de guarda, controle e distribuição informacional. Sendo assim, as tecnologias da informação são utilizadas por essas unidades, com vistas a dinamizar os processos de tratamento e organização da informação acumulada (ALVARENGA, 2006).

\footnotetext{
${ }^{2}$ Este estudo foi apresentado de forma preliminar ao IX Encontro Internacional de Catalogadores (EIC) e II Encontro Nacional de Catalogadores (ENACAT), ocorrido em novembro de 2013, Rio de Janeiro.
} 
O uso acentuado de novas tecnologias proporcionou a construção de um novo espaço de atuação profissional, abarcado por instrumentos sofisticados que acarretam, por conseguinte, "[...] mudanças nos personagens e nas instituições geradoras e armazenadoras do conhecimento humano, delegando o aparecimento de novas demandas, consequentemente, a adequação de novos perfis profissionais e institucionais [...]" (SANTA ANNA; GERLIN; SIQUEIRA, 2013, p. 1).

As bibliotecas no decorrer dos tempos vêm sendo impactadas pelas novas tecnologias da informação e comunicação (TICs), cujo poder de tratamento informacional, de armazenamento e de distribuição se consomem de forma cada vez mais eficientes, a custos mais baixos e maior agilidade nos processos realizados.

Projetadas, a priori, sob uma função custodial, as bibliotecas atravessaram várias fases ao longo da história, desfalecendo-se na atualidade como um espaço em prol de satisfazer as necessidades e exigências demandadas por seus usuários, migrando-se do paradigma da posse/guarda para o acesso. Ao analisar os diversos estágios porque passaram as bibliotecas ao longo da historiografia humana, observa-se, de modo geral, certos aspectos que permearam todos os tempos: desde os primórdios da humanidade, com os tabletes de argila até as páginas eletrônicas da internet, as bibliotecas foram se reestruturando conforme as tendências sociais, tendo o aparato tecnológico como ferramenta indissociável.

Remetendo-se dos primórdios da civilização a nossos dias, Ohira e Prado (2002, p. 61) destacam três grandes estágios que influenciaram o papel das bibliotecas e suas relações com a sociedade. $\mathrm{O}$ primeiro estágio remonta-se às bibliotecas antigas tendo o espaço físico e as atividades mecânicas como principais características. O segundo estágio se refere à utilização dos computadores e da internet como ferramental de trabalho nas práticas biblioteconômicas. Esta fase se refere à "[...] biblioteca moderna ou automatizada, em que os computadores foram usados para serviços básicos como catalogação, indexação e organização do acervo [...]". O terceiro e último período faz menção ao universo digital que por meio da internet, permite o acesso remoto às informações, bem como a autossuficiência e interatividade dos usuários. As autoras afirmam que essa época é um momento em que a biblioteca ganha nova dimensão, deixando de ter somente um espaço físico delimitado para ganhar um espaço sem fronteiras, isto é, o ciberespaço.

Cunha (2010) considera a revolução da biblioteca a partir do uso das TICs. Para esse autor existem quatro períodos marcantes na evolução tecnológica das bibliotecas: era tradicional moderna; era automatizada; era eletrônica e, por fim, virtual. As metamorfoses sofridas pelas bibliotecas ao longo das eras apontam para uma mudança crucial nas bibliotecas do terceiro milênio, pois com o advento da sociedade da informação, estas organizações adotaram um novo espaço (ciberespaço) e uma nova interface que amplia a capacidade comunicativa e interativa com os usuários mundo afora, flexibilizando a atuação do usuário em relação aos serviços e produtos por elas oferecidos. 
Deste modo surge a biblioteca digital, que para muitos também pode ser chamada de virtual. O que importa é que caminhamos para um futuro repleto de transformações em que, as práticas tradicionais tendem a se aperfeiçoar, utilizando os métodos oferecidos pelo ambiente virtual. A biblioteca do futuro se projeta a partir de novas estruturas tecnológicas que despertam um "[...] fenômeno que pode vir a minorar alguns dos problemas enfrentados pelos que pretendem resolver suas necessidades de informação por meio do contexto digital [...]" (DIAS, 2007, p. 1).

O ambiente digital traz em seu bojo inúmeras complexidades que afetam todas as instâncias sociais e profissionais, notadamente diante dos impactos vindos da globalização, que segundo Baptista (2004, p. 225) esse fenômeno econômico "[...] desemprega, mas cria, simultaneamente, outros tipos de emprego [...]".

A esse respeito, Levacov (1997) e Cunha (2010) discursam que, a biblioteca do futuro, e, paralelamente o profissional que a sustenta, não será extinto, mas deverá sofrer alterações, com base nas novas necessidades demandadas no contexto social; trata-se de adequar-se para não marginalizar-se, pois atuaremos em um ambiente diferente do tradicional, um espaço sem paredes, repleto de livros sem páginas.

Diante dos avanços tecnológicos, os serviços biblioteconômicos são afetados, cabendo ao profissional adentrar-se a novas práticas em seu fazer profissional, de modo a satisfazer a necessidade do público a que serve. Segundo Lancaster (1994) e Levacov (1997), é certo que a biblioteca do futuro entrará em um ritmo de mudanças constantes, visando adequar-se às novas tendências, às quais poderão ser vistas como oportunidades ou ameaças, cabendo aos profissionais adentrar-se à primeira alternativa, adequando-se conforme as tendências inovadoras e potencializando suas capacidades.

\subsection{Os problemas da organização da informação no espaço digital}

A organização da informação constitui uma das principais atividades desempenhas pelos profissionais da ciência da Informação. No campo específico da Biblioteconomia, o ato de organizar está representado nos processos de catalogação, indexação e classificação, cuja finalidade desses processos, a posteriori, é viabilizar os mecanismos de busca e recuperação da informação.

No entendimento de Naves (2001, p. 189), a organização da informação se torna uma atividade cada vez mais necessária, devido a dois fatores principais: a explosão informacional e a interdisciplinaridade das ciências. A autora considera que "[...] $\mathrm{O}$ aumento da produção científica, aliada à crescente interdisciplinaridade entre as áreas do conhecimento que vêm ocorrendo nas últimas décadas torna o trabalho de organização e tratamento da informação cada vez mais árduo e complexo". 
O trabalho de organizar a informação disponível está permeado por atividades típicas e clássicas do fazer do profissional da informação, formada por técnicas que conduzem ao ato de classificar, indexar e catalogar. Nesse enfoque, Naves (2001, p. 189) proclama que

\begin{abstract}
No campo da ciência da informação, a ação de identificar e descrever o conteúdo de um documento ocorre na indexação, na classificação ou na catalogação de assuntos. A indexação é considerada como processo básico na recuperação da informação e, dentro desse processo, ocorre a compreensão e a interpretação do conteúdo informativo do documento [...].
\end{abstract}

Embora a preocupação em organizar o conhecimento venha sendo discutida desde tempos antigos, é no final do século XX que essa área ganhou proporções ainda mais gigantescas, despertando atenção de pesquisadores e profissionais. Essa atenção especial é justificada devido a vários fatores, como "[...] o aumento de informação em circulação, a diversidade de suportes para seu registro e, em especial, o desenvolvimento das tecnologias da informação" (ANDRADE, 2006, p. 47).

A organização da informação é permeada por vários processos, chamados de tratamento informacional. No entendimento de Dias e Naves (2007, p.17) o processo de tratar a informação engloba um conjunto de análises que são realizadas junto ao documento, no intento de descrever ou representar descritivamente e tematicamente as características essenciais do item informacional. Assim, essa expressão engloba todas as disciplinas, técnicas, métodos e processos relativos a:

[...] a) descrição física e temática dos documentos [...]; b) desenvolvimento de instrumentos (códigos, linguagens, normas, padrões) a serem utilizados nessas descrições; e c) concepção/implantação de estruturas físicas ou bases de dados destinadas ao armazenamento dos documentos e de seus simulacros (fichas, registros eletrônicos, etc.).

O tratamento da informação engloba as disciplinas de classificação, catalogação e indexação, bem como especialidades delas derivadas, ou terminologias novas nelas aplicadas, sobretudo com o surgimento do documento digital, tais como metadados e ontologias, entre outras.

A respeito das interferências das TICs e de toda a completude do ciberespaço, profere Dias (2007, p. 74, grifo nosso) que a essência dos processos tradicionais constitui a base que norteia o fazer em ambiente virtual, exigindo mais aprimoramento dos recursos, consequentemente, adequação dos sujeitos que os manuseiam.

A aplicação dos processos e métodos de tratamento da informação exige que se definam previamente conjuntos de recursos eletrônicos a serem tratados, com os respectivos objetivos que primeiro determinaram a definição desses conjuntos. Enquanto muitos dos processos e instrumentos desenvolvidos no contexto dos sistemas tradicionais podem e deverão ser aproveitados no contexto digital, especificidades desse último exigirão que novos processos e instrumentos venham a ser desenvolvidos. 
$\mathrm{O}$ autor defende que o ambiente virtual, mesmo com suas pressões fortemente presentes possui uma dependência do trabalho tradicional, pois a essência necessária para entender e sustentar o tratamento informacional é a mesma independente da tecnologia e da plataforma de trabalho.

Entende-se que o tratamento da informação em espaço digital exigirá o conhecimento do uso das novas formas de representação, uma vez que os objetos digitais, diferentemente dos físicos, apresentam diferenças de formas e estrutura o que irá requer um domínio específico para seu gerenciamento.

Para Alvarenga (2006) a representação da informação em ambientes digitais traz a necessidade de aprimoramento de outras formas de tratamento, já que o objeto adquire novas características. Constitui objetos digitais, os textos das mais variadas natureza, imagens, sons, sítios, listas de discussão, software em geral, protocolos e outros dispositivos necessários à implementação das tecnologias informáticas.

Atrelado a esse contexto, é perceptível que uma das mais evidenciadas características do ambiente virtual é sua capacidade de interatividade, pois as instâncias de tempo e de espaço não constituem limites. Nesse espaço de integração, a troca de informações se faz necessária, o que remete à necessidade de intertextualidade entre os vários documentos compartilhados.

Ao organizar a informação digital, o profissional deverá adentrar-se às inúmeras possibilidades de relacionamento que se possam estabelecer entre os diversos documentos, o que caracteriza o documento hipertextual. Lima (2006) define hipertexto como um documento eletrônico que permite uma leitura não sequencial, com similaridades com a leitura flexível e com o raciocínio humano.

Essa flexibilização torna o documento propenso a mutações, tendo o leitor a capacidade em controlá-lo, relacionando-o com outros objetos ou contextos, aumentando com isso, "[...] as relações possíveis entre as imagens, os sons e os textos associados de maneira não-linear, mediante conexões eletrônicas, assim como as ligações realizadas entre os textos fluidos em seus contornos e em número virtualmente ilimitado [...]" (CHARTIER, 2002, p. 108-109, grifo nosso).

Nesse contexto, Lima (2006) defende que a organização hipertextual se assemelha à indexação tradicional. Porém, adverte para questões problemáticas que requerem o aperfeiçoamento das TICs a fim de permitirem o tratamento técnico dos objetos digitais. Devido à falta de limitação, típica do espaço, a catalogação, indexação ou classificação não podem ser aferidas da mesma forma que eram realizadas com documentos em formato físico.

Embora Dias (2007) defenda que as práticas tradicionais transferem-se para a plataforma digital, é preciso frisar que, as complexidades do espaço digital requerem métodos mais extensivos no sentido de abarcar a imensa gama de informação, bem como a 
delimitação de técnicas mais elaboradas que possam assegurar a integridade dos documentos hipertextuais.

Diante dessas complexidades, observa-se a necessidade dos catalogadores em aprimorar seus métodos de trabalho, tendo em vista a contribuição de seu trabalho em bibliotecas virtuais. O tratamento da informação possui como finalidade central facilitar o processo de recuperação das informações. Quando esse tratamento é feito a documentos presentes na rede, o processo de organização requer mais cautela, o que depreende a necessidade de valorização do profissional que atua nesses ambientes. Ademais,

[...] fica clara a importância do classificador/indexador/catalogador que, por meio de uma análise de assunto anterior, considera tanto o contexto quanto o conteúdo do termo. O classificador/indexador/catalogador também identifica os conceitos, dividindo-os segundo categorias, estabelecendo uma estrutura que ajude os usuários em suas pesquisas (LIMA, 2006, p. 107).

Um dos principais problemas do hipertexto é um efetivo direcionamento do leitor, especialmente na fase de escolha dos vínculos na estruturação da informação hipertextual. Essa organização deve refletir a estrutura conceitual ou a rede semântica do assunto a que se relaciona, pois "[...] se a informação for disposta de maneira organizada, será mais provável e mais fácil, em tese, localizar e procurar o que se procura [...] (LIMA, 2006, p. 110)".

Como se observa, as bibliotecas virtuais, graças às contribuições das inovações tecnológicas, abarcarão infinidades de fontes de informação, podendo ser compartilhadas mundo afora, porém, como consequência dessa ascensão, ocasiona-se sérios problemas de organização catalográfica, que devem ser gerenciados com novos métodos a fim de estabelecer um controle sobre o que a biblioteca oferece em concomitância com o que a comunidade usuária necessite.

Especificamente, ao trabalho dos catalogadores digitais, Drabenstott e Burman (1997) perceberam um futuro esperançoso, defendendo que esses profissionais devam romper com métodos simplistas e limitados, típicos do ambiente tradicional, pois eles não atendem integralmente todos os pormenores dos documentos em formatos digitais.

Os mesmos teóricos defendem que a catalogação automática ganha nova abordagem, sendo controlada por indivíduos detentores de conhecimento cibernético, estabelecendo ligações entre os materiais digitais, tais como livros, revistas e outros formatos a serem ainda inventados. Além do trabalho técnico propriamente dito, faz-se necessário o trabalho interdisciplinar a ser realizado em ambiente digital, de modo que se ofereça apoio a trabalhos enciclopédicos e aos usuários que procuram informação, desde os novatos aos acadêmicos, pelos conhecimentos que devem possuir em áreas particulares de assunto.

\subsection{Definindo novos instrumentos, métodos e práticas}

Embora pareça complexo o desafio que a sociedade nos apresenta, diante da importância e da produção/consumo acelerado de informação, o controle informacional pode 
ser melhor viabilizado através das técnicas estabelecidas pela Organização da Informação, em especial as contribuições advindas da Catalogação, ao oferecer os princípios básicos para armazenar e disseminar informação, evitando, desse modo, um caos informacional. É por meio da indexação, catalogação e classificação e suas nuances que o gerenciamento informacional é efetivado.

Para tanto, faz-se necessário o uso, como em qualquer área do conhecimento ou atuação profissional, da utilização de métodos e técnicas específicos que assegurem as atividades essenciais da profissão, melhorando as relações dos sujeitos, seus comportamentos e resolução de problemas. Na área da Catalogação, uma multiplicidade de metodologias é utilizada pelos profissionais no intento de atingir os objetivos centrais do trabalho profissional. Aliados às inúmeras metodologias estão os instrumentos de trabalho, que em conjunto, forma o ferramental necessário para que as atividades sejam realizadas com êxitos.

Tradicionalmente, Dias e Naves (2007) conferem que, as atividades dos profissionais que lidam com tratamento da informação se resumem a: produtos, processos e instrumentos. Os processos compreendem as atividades de trabalho em si, como a catalogação, classificação e indexação. Esses processos geram produtos que irão auxiliar a entender a dinâmica da recuperação da informação. Por sua vez, os instrumentos são as estruturas que o bibliotecário utiliza durante a realização de um processo específico, constituindo nessa categoria: os tesauros, os esquemas de classificação, as linguagens documentárias, dentre outros.

Ao transportar-se para o ambiente virtual, a biblioteca irá realizar os mesmos processos, porém com estruturas diferenciadas, tendo os objetos presentes na plataforma digital diferentes formas. A partir dessa afirmação, entende-se que a essência do processo permanece a mesma, o que muda é o método, o jeito de fazer, como fazer e para quem fazer. Nas palavras de Alvarenga:

\footnotetext{
O conceito pode ser visto como fator invariante na concepção e tratamento de documentos, quando se fala da evolução das bibliotecas tradicionais para as digitais. Daí a complexidade das propostas de tratamento automático de objetos digitais, estando envolvidas, nesse processo, velhas soluções com novas designações. Mudam-se os meios, sofisticam-se os instrumentos e surgem nomes novos para designar coisas novas e velhas. Entretanto, a essência das coisas permanece (ALVARENGA, 2006, p. 97, grifo nosso).
}

Partindo dessa constatação defendida por Alvarenga (2006), depreende-se que muitos procedimentos utilizados na catalogação, muitas ferramentas que já deixaram de ser utilizadas, na verdade, transmitiram a essência do processo realizado para ferramentas mais modernas. Nesse aspecto, é uma característica inexorável da sociedade tecnológica: a obsolescência do instrumental utilizado.

Durante o processo de organização da informação em bibliotecas digitais, os termos atribuídos às várias práticas utilizadas no tratamento documental, como catalogação, 
indexação e classificação estão sendo substituídos aos poucos por terminologias relacionadas à área da informática.

Desse modo, em linhas gerais, as duas grandes etapas do processo de Catalogação, qual seja, o tratamento temático e o descritivo adquirem nas bibliotecas digitais, outras nomenclaturas: os metadados e as ontologias, cuja função se encarregam em oferecer todas as condições diversificadas para representação dos objetos digitais, sob inúmeras possibilidades.

O termo metadados faz menção ao tratamento descritivo, que no ambiente tradicional era permeado pela catalogação e classificação. No espaço digital, o trabalho volta-se para a tentativa de criar ou viabilizar pontos de acessos para os documentos disponibilizados em bases de dados. Já o termo ontologias se restringe ao ato de indexar, ou seja, refere-se ao tratamento temático da informação, com vistas à construção de vínculos, sejam hierarquizados ou relacionais entre os documentos digitais existentes no ciberispaço (DIAS; NAVES, 2007).

O conceito de metadado possui sua gênese na área da Ciência da Computação, sendo utilizado para descrever ou representar um objeto na forma interfaciada pelo computador. A estrutura do metadado o permite ser identificado e compreendido por máquinas (CAMPOS, 2007).

A literatura em geral considera metadado como o dado sobre dado, porém essa expressão pode ser melhor compreendida ao significar uma informação preliminar sobre algo, a ser identificada pelo usuário antes deste acessar a fonte original. Desse modo, constituem "[...] "dados associados com objetos que desoneram os usuários potenciais de ter conhecimento completo antecipado da existência e características desses objetos" (CAMPOS, 2007, p. 19, apud DEMPSEY; HEERY, 1997) ${ }^{3}$.

Importante atentar para o fato de que o metadado representa não o objeto em si, mas um recurso, seus atributos, gerenciamento e uso. Por conseguinte, o metadado representa um dado que descreve atributos de um recurso, caracteriza [...] suas relações, apoia sua descoberta e uso efetivo, e existe em um ambiente eletrônico. Usualmente, consiste em um conjunto de elementos, cada qual descrevendo um atributo do recurso, seu gerenciamento ou uso" (CAMPOS, 2007, p. 19, apud VELLUCCI, 1998, p. 192) ${ }^{4}$.

A ontologia pode ser entendida de inúmeras formas, desde disciplina da Filosofia, como da Informática, estendendo-se para o contexto da arquitetura informacional. Sua essência, ao ser abordada pela Catalogação se restringe à "[...] faceta semântica da representação de seres, entes, assuntos, e conteúdos temáticos relativos a objetos digitais" (ALVARENGA, 2006, p. 92).

\footnotetext{
${ }^{3}$ DEMPSEY, L.; HEERY, R. Desire: development of an European Service for Information on Research and Education. Unión Europea, 1997.

${ }^{4}$ VELLUCCI, S. L. Metadata. Annual Review of Information Science and Technology, v. 33, 1998.
} 
As ontologias assemelham-se ao processo de análise temática realizada em um item de informação e suas várias relações com os demais itens existentes em uma base de dados. "O conceito em ontologia compõe desde as classes, mais gerais, até as instâncias. Mesmo as relações (propriedades e atributos das classes) são basicamente conceitos que caracterizam e completam o sistema terminológico da ontologia" (GONÇALVEZ; SOUZA, 2013, p. 2).

O que se observa é a amplitude da ontologia quando comparada aos tradicionais instrumentos que estabelecem conceitos e relações entre termos, como as linguagens de indexação. As ontologias se diferem das linguagens taxonômicas, pois estas se limitam aos relacionamentos hierárquicos, enquanto a ontologia presa pelo relacionamento associativo, despertando inúmeras combinações entre variados termos (CURRÁS, 2010; VIDAL, CAFÉ, 2011).

Nesse enfoque, percebe-se que o ambiente digital requer instrumentos de trabalho mais sofisticados que os tradicionais, devido às complexidades dos documentos digitais. No que se refere ao processo de classificação, é pertinente questionar até que ponto os tradicionais esquemas de classificação delinearão limites entre as classes a serem classificadas. Alvarenga (2006) afirma que a classificação ainda não é uma constante nos acervos digitais. Na visão dessa autora as categorias de Aristóteles, retomadas com ligeiras alterações por Ranganathan e que propiciam a análise dos conceitos em ângulos diversos de abordagem, as facetas, têm sido consideradas por muitos, como uma alternativa para a organização semântica, vislumbrada como insumo potencial para a criação de novas ferramentas destinadas à resolução do grande problema atual da ciência, situada na confluência dos processos de produção, representação e organização de conhecimentos.

Com efeito, convém destacar, os inúmeros esforços que já vêm sendo envidados no sentido de aprimorar os tradicionais instrumentos de catalogação. Os códigos de catalogação até então utilizados nas bibliotecas tradicionais, são expandidos para um instrumento mais exaustivo, mencionando regras de representação para itens em formato físico quanto digital, uma alternativa válida e consistente para atender a maioria das bibliotecas na modernidade: as unidades híbridas.

O novo código que visa substituir o Código de Catalogação Anglo-Americano (AACR2) é a Resource Description and Access (RDA). A RDA constitui, em sentido lato, um novo código de catalogação que além de recomendar instruções bibliográficas para documentos impressos, também apresenta as descrições para obetos digitais, ampliando as capacidades do AACR2. Para Silva (2012, p. 114):

A nova realidade digital presente com a Web levou a uma nova abordagem, tendo como princípio norteador o foco nos usuários e suas necessidades na obtenção da informação. Neste cenário, uma revisão para ir ao encontro das novas necessidades conceituais e formais da descrição bibliográfica era necessária, não sendo possível apenas uma revisão de regras existentes já estabelecidas nas AACR2.

A mesma autora explica que nas datas de 1960 e 2000, a catalogação passou por um grande número de mudanças, tanto pela diversidade nas publicações como por novas formas 
de conteúdo e de plataformas de informação, alterando a maneira dos profissionais e também dos usuários de bibliotecas lidarem com a substância dos assuntos. A RDA é projetada para lidar com estas novas dinâmicas agora em um ambiente digital.

\subsection{Uma nova identidade para os catalogadores: os cibertecários}

As inovações tecnológicas têm se constituído como a "mola propulsora" para a Catalogação, tornando possível o gerenciamento efetivo das informações produzidas nos vários segmentos da sociedade e a viabilidade de distribuí-la a todos os usuários que delam precisam para se manterem atualizados e preparados a vencer os desafios de uma era instável e competitiva.

A partir desse propósito, percebe-se que as áreas que possuem a informação como objeto de estudo, notadamente a biblioteconomia, foi influenciada por pressões que a direcionou para novos rumos, em busca da formulação de novas concepções paradigmáticas, no intento de satisfazer as necessidades demandas pelos usuários.

A tecnologia da informação e comunicação proporcionaram (e proporcionam) mudanças nas atividades realizadas pela Catalogação, isto graças à capacidade de armazenar, recuperar e disseminar informações sem considerar a questão de tempo e espaço, disseminando informações em um período de tempo cada vez menor, além de baixo custo. Todavia, esses processos não proporcionam o desaparecimento da profissão, mas o seu o remodelamento, a transformação de uma atuação profissional diferenciada, uma vez que "[...] as tecnologias de ponta trazem novas oportunidades, novas dicas para melhorar o exercício profissional” (SANTA ANNA; GERLIN; SIQUEIRA, 2013, p. 7).

Desse modo os profissionais se veem diante de um novo espaço de trabalho, permeado pelas diversificadas ferramentas tecnológicas que exigem novos métodos de trabalhos a serem incorporados no fazer bibliotecário. Para Madureira e Vilarinho (2010, p. 103) vive-se na atualidade "[...] um processo evolutivo das bibliotecas e o bibliotecário precisa se preparar para assumir sua identidade de 'cibertecário'. Nesse sentido, ele é um desbravador, um pioneiro e o que produzir será a base de uma nova visão de biblioteca e informação".

A nova nomenclatura "cibertecário" é recente na literatura, tendo poucos estudos que a descreve, porém entende-se que essa terminologia está perfeitamente adequada ao momento de transição que as bibliotecas atravessam nesse início de milênio. As mesmas autoras defendem que o cibertecário deve se adequar a algumas exigências, como: adequar-se as TICs, ser criativo inovando constantemente os métodos e instrumentos de trabalho e por fim, atuar de forma inter e multidisciplinar, disseminando informação precisa, conforme as demandas.

A respeito das mudanças na formação profissional, é importante atentar para o fato de que mesmo passando por mudanças de perfis, os profissionais continuarão contribuindo com suas competências, habilidades e inteligência, aperfeiçoando seus métodos de trabalho a visar 
uma prática profissional mais efetiva, consolidada pelas novas oportunidades tecnológicas, que transformam os métodos tradicionais, mas não os eliminam (SANTA ANNA; GERLIN; SIQUEIRA, 2013, p. 6).

Mesmo nas bibliotecas hibridas, em que convergem modalidades mistas de documentos (físico e digital) a presença das TICs já se acentua. Os informatas adquirem a cada dia, novos postos de trabalho em meio às constantes atividades de catalogação bibliográfica, construindo bases de dados, através de modelagem, construção de catálogos em linhas, sistemas para catalogação dentre tantas outras atividades abarcadas pelas TICs. Portanto, se o catalogador não se portar como cibertecário, outros farão tais atividades (DRABENSTOTT; BURMAN, 1997). Assim,

O bibliotecário, portanto, deve ir à luta, posicionar diante das mudanças existentes ao acesso à informação pelas redes eletrônicas, [...]. É preciso que se aproveite a oportunidade para demonstrar a importância de seus conhecimentos, experiência e identificação profissional na manipulação da informação e atendimento aos usuários, bem como se assente qual seja o seu novo "fazer" neste contexto digital (DRABENSTOTT; BURMAN, 1997, p. 15).

Para se atingir essa missão de adentrar-se a novos perfis, aprimorando constantemente suas práticas, duas ações se fazem necessárias após a formação acadêmica na área: é preciso valorizar a formação continuada e a interdisciplinaridade com métodos de adaptação mais confiáveis.

De acordo com Baptista (2004) o trabalho desenvolvido por equipes interdisciplinares conduzirão os processos de trabalho a atingir a excelência, pois uma pessoa sozinha não consegue ter sucesso em todas as áreas: softwares, linguagens de programação, redes de transmissão e de segurança, organização do conteúdo, planejamento, gerência, conversão de acervo para o meio digital, marketing, design, dentre todas as outras atividades permeadas nas contingências de bibliotecas virtuais e híbridas.

No que diz respeito à formação continuada do catalogador, Baptista (2004) afere que as mudanças no mercado de trabalho fazem com que este profissional busque a continuidade de sua educação, pois com a diversidade de áreas e possibilidades que a profissão apresenta, é preciso estar atento às inovações e tendências atuais. Neste sentido, as entidades de classe buscam junto a seus associados, viabilizar este propósito, divulgando e promovendo cursos e eventos da área.

Em linhas gerais, o êxito profissional dos catalogadores em ambientes virtuais (cibertecários), somente será evidenciado se ele adquirir as mesmas funções de um Moderno Profissional da Informação, ou seja, profissional que tenha

[...] mente aberta, atentos e flexíveis, capazes de enfrentar os desafios impostos pelas mudanças. A multiplicidade de suportes e sua variedade de usos passaram a exigir um profissional com mais conhecimentos e, por conseguinte, habilidades, que põem em questão os rigorosos limites profissionais restritos à graduação [...] (MADUREIRA; VILARINHO, 2010, p. 91, grifo nosso). 
A constatação das autoras evidencia a necessidade de melhorar o processo de formação, por meio de mudanças curriculares, capacitando os catalogadores ao tratamento do novo tipo de documento da contemporaneidade: o documento em suporte digital. Os catalogadores precisam valorizar a capacitação profissional, a participação em treinamentos, aquisição e domínio de novas mídias, dentre outros conhecimentos que devem ser desenvolvidos, sobretudo, o costume e domínio de instrumentos catalográficos digitais.

Semelhantemente a outras mudanças ocorridas no perfil dos bibliotecários brasileiros nas últimas décadas do século XX (de profissional erudito e humanista a um profissional técnico), é o momento de nova metamorfose profissional, principalmente na área da Catalogação Digital, o que remete à migração: de catalogador a cibertecário, no intento de enfrentar as transformações do novo milênio e as complexidades dos documentos digitais.

\section{CONSIDERAÇÕES FINAIS}

De acordo com os estudos realizados nas literaturas investigadas, foi possível constatar que as novas tecnologias vêm proporcionando grande valor na área da Organização da Informação em ambientes digitais, em especial, aos procedimentos de representação informacional, a Catalogação. O uso intenso de novos artefatos converge para uma situação paradoxal: por um lado os benefícios trazidos são de grande valia, devido à alta capacidade de armazenamento, processamento e transmissão de informação; por outro lado, acometem a muitos profissionais o temor a respeito desses avanços, colocando a tecnologia como excludente dos procedimentos realizados na Catalogação Digital.

Com a (r)evolução tecnológica, os documentos digitais adquirem novas formas, exigindo representações mais complexas das realizadas em documentos tradicionais. Assim, surgem novos procedimentos a serem realizados, com novas terminologias, mas que, em essência, exigirá a habilidade dos profissionais catalogadores.

Utilizando-se das potencialidades proporcionadas com o uso de novas tecnologias, novos conceitos surgem no âmbito da Catalogação, como ontologias e metadados, constituindo, respectivamente, organização e representação formal dos itens informacionais ao serem tratados no espaço digital. Devido a esse novo contexto, as atividades de catalogação demandarão de instrumentos mais sofisticados a fim de atender as especificações dos objetos digitais. Surge, assim, novos instrumentos catalográficos, como a RDA, que visa a evolucionar as lacunas não abarcadas pelo tradicional AACR2, atendendo a amplitude do ambiente digital.

Por fim, o estudo sugere uma nova nomenclatura atribuída aos catalogadores, que semelhantemente às transformações pela qual passam todos os profissionais da informação, ao atuarem em ambiente virtual, adquirem a denominação de cibertecários, gerenciando o espaço digital, com vistas a transformá-lo em um centro de disseminação/compartilhamento e não de guarda e armazenamento. 
Para que catalogadores adquiram as novas competências exigidas para atuação em ambiente digital, transformando-se em cibertecários, vislumbra-se a necessidade de adquirirem as competências de um moderno profissional da informação, tendo a formação continuada como principal aliada nessa conquista. Por meio de cursos e treinamentos acerca da catalogação em ambiente digital, familiarizando-se como novos formatos, linguagens e formas de representação digital, o catalogador será um cibertecário em atuação, representando a informação digital da forma mais adequada para seu gerenciamento e recuperação.

\section{REFERÊNCIAS}

ALVARENGA, Lidia. Organização da informação nas bibliotecas digitais. In: NAVES, Madalena Martins Lopes; KURAMOTO, Hélio (Org.). Organização da informação: princípios e tendências. Brasília: Briquet de Lemos, 2006.

ANDRADE, Maria Eugênia Albino. Um olhar sobre representações no universo do conhecimento: o caso das micro e pequenas empresa. In: NAVES, Madalena Martins Lopes; KURAMOTO, Hélio (Org.). Organização da informação: princípios e tendências. Brasília: Briquet de Lemos, 2006.

BORGES, Jorge Luis. Ficções. São Paulo: Abril Cultural, 1972.

BAPTISTA, Sofia Galvão. As oportunidades de trabalho existentes na internet na área de construção de páginas de unidade de informação. In: ; MUELLER, Suzana Pinheiro Machado (Org.). Profissional da informação: espaço de trabalho. Brasília: Thesaurus, 2004.

CAMPOS, Luiz Fernando de Barros. Metadados digitais: revisão bibliográfica da evolução e tendências por meio de categorias funcionais. Enc. Bibli: R. Eletr. Bibliotecon. Ci. Inf., Florianópolis, n. 23, n. 1, 2007. Disponível em: <www.brap ci.ufpr.br/download.php?dd0=11673 >. Acesso em: 20 ago. 2013.

CHARTIER, Roger. Os desafios da escrita. São Paulo: UNESP, 2002.

CUNHA, Murilo Bastos da. A biblioteca universitária na encruzilhada. DataGramaZero Revista de Ciência da Informação, v.11, n.6, dez. 2010. Disponível em: <http://www.datagramazero.org.br/dez10/Art_07.htm>. Acesso em: 20 fev. 2013.

CURRÁS, Emilia. Ontologias, taxonomia e tesauros: em teoria de sistemas e sistemática. Brasília: Thesaurus, 2010.

DIAS, Eduardo Wense; NAVES, Madalena Martins Naves (Org.). Análise de assunto: teoria e prática. Brasília: Thesaurus, 2007. 
DIAS, Eduardo Wense. Organização da informação no contexto das bibliotecas tradicionais e digitais. In: NAVES, Madalena Martins Lopes; KURAMOTO, Hélio (Org.). Organização da informação: princípios e tendências. Brasília: Briquet de Lemos, 2007.

DRABENSTOTT, Karen; BURMAN, Celeste. Revisão analítica da biblioteca do futuro. Ci. Inf., v.26, n.2, 1997. Disponível em: 〈http://www.scielo.br/pdf/ci /v26n2/v26n2-11.pdf〉. Acesso em: 20 ago. 2013.

GONÇALVEZ, Julia; SOUZA, Renato Rocha. Relações e conceitos em ontologias: teorias de Farradane e Dahlberg. In: Seminário de pesquisa em ontologia no Brasil. Universidade Federal Fluminense. Departamento de Ciência da Informação. Niterói. 2013. Disponível em: <http://www.uff.br/ontologia/artigos/15.pdf >. Acesso em: 20 ago. 2013.

KURAMOTO, Hélio. Sintagmas nominais: uma abordagem no processo de indexação. In: NAVES, Madalena Martins Lopes; KURAMOTO, Hélio (Org.) Organizaçãa da informação: princípios e tendências. Brasília: Briquet de Lemos, 2006.

LANCASTER, F. Ameaça ou Oportunidade?: o Futuro dos Serviços de Biblioteca à Luz das Inovações Tecnológicas. Revista da Escola de Biblioteconomia UFMG, Belo Horizonte, v. 23, n. 1, p.7, jan./jun. 1994.

LEVACOV, Marília. Bibliotecas virtuais: (r)evolução? Ci. Inf., v. 26, n. 2, 1997. Disponível em: <http://www.scielo.br/pdf/ci/v26n2/v26n2-2.pdf>. Acesso em: 1 abr. 2013.

LIMA, Gercina Ângela Borem. Organização da informação para sistemas de hipertextos. In: NAVES, Madalena Martins Lopes; KURAMOTO, Hélio (Org.). Organização da informação: princípios e tendências. Brasília: Briquet Lemos, 2006.

MADUREIRA, Helaina Oliveira; VILARINHO, Lucia Regina. A formação do bibliotecário para atuar em bibliotecas digitais: uma questão a aprofundar. Perspectivas em Ciência a Informação, v.15, n.3, p.87-106, set./dez. 2010.

NAVES, Madalena Martins Lopes. Estudo de fatores interferentes no processo de análise de assunto. Perspect. Cienc. Inf., Belo Horizonte, v. 6, n. 2, p. 189-203, jul./dez. 2001.

OHIRA, Maria Lourdes Blatt; PRADO, Noêmia Schoffen. Bibliotecas virtuais e digitais: análise de artigos de periódicos brasileiros (1995/2000). Ci. Inf., Brasília, v. 31, n. 1, p. 6174, jan./abr. 2002.

SANTA ANNA, Jorge; GERLIN, Meri Nadia; SIQUEIRA, Poliana. A tecnologia da informação e seus reflexos no serviço de referência da Biblioteca Central da UFES. In: Congresso Brasileiro de Biblioteconomia e Ciência da Informação, 25, Florianópolis, 
Anais Eletrônicos..., 7 a 10 de julho de 2013. Disponível em: < http://xx vcbbd.fe bab.org.b r/programa cao/>. Acesso em: 2 out. 2013.

SILVA, Eliana Barboza de Oliveira. Conceituação e aplicação do novo padrão para descrição bibliográfica. CRB-8 Digital, São Paulo, v. 1, n. 5, p. 113-123, jan. 2012. Disponível em: < http://revista.crb8.org.br>. Acesso em: 20 ago. 2013.

VIDAL, Luciane Paula; CAFÉ, Lígia Maria Arruda. Ontologias e taxonomias: diferenças. Perspectivas em Ciência da Informação, v.16, n.2, p.115-130, abr./jun. 2011. Disponível em: <http://portaldeperiodicos.eci.ufmg.br/inde x.php/pci/article/view/200/927>. Acesso em: 21 ago. 2013.

Como citar este documento:

SANTA ANNA, Jorge. A (r)evolução digital e os dilemas para a catalogação: os cibertecários em atuação. Revista Digital de Biblioteconomia e Ciência da Informação, Campinas, SP, v. 13, n. 2, p. 312-328, maio/ago. 2015. ISSN 1678-765X. Disponível em: <http://periodicos.bc.unicamp.br/ojs/index.php/rdbci/article/view/8634632>. Acesso em: 31 maio 2015. 